\section{Tropical Journal of Ophthalmology and Otolaryngology}

\title{
A clinical study to determine the effects of adenoidectomy in cases of secretory otitis media in school going children
}

\author{
Santosh D. ${ }^{1}$, Sumanth D. ${ }^{2 *}$, Veeranjaneyulu P. ${ }^{3}$, Deepthi B. ${ }^{4}$, Mamatha K. ${ }^{5}$ \\ DOI: https://doi.org/10.17511/jooo.2020.i08.01
}

\footnotetext{
${ }^{1}$ B Krishna Santosh, Associate Professor, Department of ENT, GSL Medical College, Rajahmundry, Andhra Pradesh, India.

${ }^{2 *}$ K Krishna Sumanth, Assistant Professor, Department of ENT, GSL Medical College, Rajahmundry, Andhra Pradesh, India.

3 Panda Veeranjaneyulu, Professor and Head, Department of ENT, GSL Medical College, Rajahmundry, Andhra Pradesh, India.

${ }^{4}$ Deepthi B, Junior Resident, Department of ENT, GSL Medical College, Rajahmundry, Andhra Pradesh, India.

5 Mamatha K, Junior Resident, Department of ENT, GSL Medical College, Rajahmundry, Andhra Pradesh, India.
}

Introduction: Secretory Otitis media (SOM) is the leading cause of hearing loss in children. Despite numerous studies on the prevention and treatment of SOM during the past decades, its management remains challenging and controversial. A study was conducted to find the effect of adenoidectomy in cases of SOM with hypertrophied adenoids and to determine the effect of adenoidectomy on hearing as assessed by the pure tone and impedance audiometry. Material and Methods: Children aged $5-12$ years, diagnosed as SOM with adenoid hypertrophy were included. The study was conducted from April 2019 to May 2020, in the department of ENT, GSL Medical College. A detailed history and clinical examination were done. Investigations such as pure tone audiogram, impedance audiometry, X-ray nasopharynx, and diagnostic nasal endoscopy were carried out to confirm the diagnosis. Results: Out of the 50 participants, a maximum (60\%) belonged to the $5-7$ years age group, the male-female ratio was 1.2. Hard of hearing was a common symptom in $66 \%$, tonsillitis, and sinusitis in $36 \%$ and $18 \%$ respectively. On pure tone audiometry, the average hearing loss was $24.95 \mathrm{~dB}$. Conclusion: Adenoidectomy in children having hypertrophied adenoids with SOM, not only relieves Eustachian tube obstruction but also removes the source of infection. This leads to clearance of middle ear effusion and improvement in hearing postoperatively.

Keywords: Secretory otitis media, Adenoidectomy, Audiometry, Children

Corresponding Author

Dr. K Krishna Sumanth, Assistant Professor, Department of ENT, GSL Medical College, Rajahmundry, Andhra Pradesh, India. Email: sankris81@yahoo.com
How to Cite this Article

Santosh BK, Sumanth KK, Veeranjaneyulu P, Deepthi B, Mamatha K. A clinical study to determine the effects of adenoidectomy in cases of secretory otitis media in school going children. Trop J Ophthalmol Otolaryngol. 2020;5(8):200-206. Available From

https://opthalmology.medresearch.in/index.php/jooo /article/view/163
To Browse

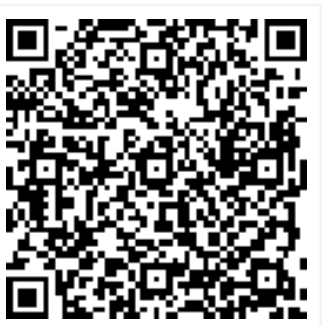

Review Round 1 2020-10-05

Funding Nil

Review Round 2
2020-10-20
Ethical Approval
Yes

Review Round 3

Accepted 2020-11-24

Plagiarism X-checker $7 \%$

(C) 2020 by Dr. B Krishna Santosh, Dr. K Krishna Sumanth, Panda Veeranjaneyulu, Deepthi B, Mamatha K and Published by Siddharth Health Research and Social Welfare Society. This is an Open Access article licensed under a Creative Commons Attribution 4.0 International License https://creativecommons.org/licenses/by/4.0/ unported [CC BY 4.0]. 


\section{Introduction}

Secretory otitis media (SOM) is one of the most common medical problems of childhood. It is the leading cause for office visits a common reason for prescribing antibiotics and the most frequent reason that children undergo surgery $[\mathbf{1}, 2]$. There are many challenges in the management of an otitisprone child. Increasing antibiotic consumption is related to the emerging phenomenon of antimicrobial resistance [3].

When the long-term impact of SOM is considered, surgical therapy is the most cost-effective than medical therapy for severe cases [4]. Historically, myringotomy, adenoidectomy, tympanostomy tubes, and even tonsillectomy have been advocated [4].

SOM is the leading cause of hearing loss in children. Prolonged or fluctuating hearing impairment in early childhood may result in long-term consequences for speech and language development.

Eustachian tube (ET) dysfunction is the universal finding in children with SOM. Adenoidectomy is being increasingly used for the treatment of SOM because recent studies have confirmed its effectiveness. The historical rationale for the removal of adenoids in children with SOM has been enlargement causing nasal obstruction and mouth breathing. The other classic rationale for removal is an improvement in ET function [4].

With these, a study was conducted to find the effect of adenoidectomy in cases of SOM with hypertrophied adenoids and to determine the effect of adenoidectomy on hearing as assessed by the pure tone and impedance audiometry.

\section{Material and Methods}

Study design: It was a prospective study, carried in the department of ENT, GSL Medical College, Rajahmundry.

Study duration: This study was carried out from April 2019 to May 2020, for one year.

Study population: A total of fifty cases were studied, who attended ENT Department, who was diagnosed to have bilateral SOM confirmed by otoscopy, PTA, impedance audiometry, and adenoid hypertrophy confirmed by X-ray Nasopharynx and diagnostic nasal endoscopy (DNE).
Sample size: During the study period, all the individuals with bilateral SOM confirmed by otoscopy, those who satisfied the study protocol were considered.

Ethical approval: The study protocol was approved by the institutional ethical committee.

Inclusion criteria: Patients aged $5-12$ years, chronic cases of bilateral SOM with adenoid hypertrophy were included in the study.

Exclusion criteria: Patients with acute /chronic suppurative otitis media (OM), individuals who did not submit the informed consent, those with a congenital deformity - cleft palate, down's syndrome, and craniofacial anomalies were not considered.

Data collection: Adequate history was taken. Detailed ear, nose, throat, and systemic examination was performed. Symptoms like nasal obstruction, snoring, nasal discharge, the hardness of hearing, fullness in-ear, and sore throat were recorded. Otoscopic findings like dull, lustreless, amber-colored, or retracted tympanic membrane or air bubbles were recorded.

The hearing threshold of both ears was determined by pure tone audiometry (PTA). The average of air conduction at 500,1000, 2000, and $4000 \mathrm{~Hz}$ was taken. Pure Tone Audiometer used was Elkon Giga 3. Hearing impairment was classified as per Clark's classification [5].

Tympanometry was done in all children confirming patency of external auditory canal and Stapedial reflux was recorded. A probe tone of $226 \mathrm{~dB}$ was used and a pressure range between -400 to +200 daPa was recorded. The graphs obtained were noted as type $A$ (normal compliance), type B (OME), type $C 1$, and type C2 (reduced compliance or early stages of OME). The simplest type of peaked/nopeaked classification was used to quantify results [6]. Nasopharynx lateral view X-ray and preoperative DNE were done to confirm adenoid hypertrophy. X-ray paranasal sinuses - Waters view was taken in patients with associated sinusitis. Other basic investigations were also carried.

All patients were medically managed for at least 3 months before being posted for surgery. Tonsillectomy was also planned. Surgeries were done under general anesthesia. Adenoids were shaved with adenoid curette taking care not to injure the $\mathrm{E}$. Tube opening in the nasopharynx. 
Complete removal was confirmed with an endoscopy. Tonsillectomy was done with the dissection and snare method. Postoperatively all patients were treated with antibiotics, decongestants, and antihistamines. They were discharged after 24 hours. All patients were followed up after one week and then at the 1st, 3rd, and 6th month of surgery, PTA was done to assess improvement in hearing. Impedance Audiometry was also done at the 6th month to see for the occurrence of the peak. Any respiratory infection during this period was promptly treated.

Statistical analysis: Statistical analysis was performed using SPSS software version 20.0 and MS Excel-2007. Descriptive statistical data such as mean, standard deviation, and percentages were considered in this research. Independent sample $t$ was used to find the significant change of pure tone audiometry findings between preoperative and postoperative results.

\section{Results}

In this report, a total of 50 SOM cases with adenoid hypertrophy was studied. The incidence of secretory OM was highest $(60 \%)$ in the $5-7$ years age group (Table 1 ). The average age of secretory OM was 7.5 years of age. Gender-wise, 28 (56\%) were males and 22 (44\%) females; the male-female ratio was 1.2 .

Table-1: Age-wise distribution of the study participants.

\begin{tabular}{|l|l|l|}
\hline \multicolumn{1}{|c|}{ Age } & \multicolumn{1}{c|}{ Number } & \multicolumn{1}{c|}{ Percent } \\
\hline $5-7$ & 30 & 60 \\
\hline $8-10$ & 11 & 22 \\
\hline $11-12$ & 9 & 18 \\
\hline Total & 50 & 100 \\
\hline
\end{tabular}

All patients $(100 \%)$ in this study were presented with nasal obstruction/snoring. This is followed by nasal discharge $(80 \% ; 40)$, hard of hearing $(66 \%$; $33)$, sore throat $(36 \% ; 18)$, and fullness of ear (24\%; 12) (Table 2). When associated morbidity was considered, 36\% (18) members had associated tonsillitis and $18 \%$ (9) were features of sinusitis.

Table-2: Presenting symptoms of the study participants.

\begin{tabular}{|l|l|l|}
\hline \multicolumn{1}{|c|}{ Symptoms } & Number & \multicolumn{1}{c|}{ Percent } \\
\hline Nasal obstn/ snoring & 50 & 100 \\
\hline Nasal discharge & 40 & 80 \\
\hline Hard of hearing & 33 & 66 \\
\hline
\end{tabular}

\begin{tabular}{|l|l|l|}
\hline Fullness of ear & 12 & 24 \\
\hline Sore throat & 18 & 36 \\
\hline
\end{tabular}

Otoscopic findings of the tympanic membrane (TM) showed the dull, lustreless, amber color was the most common $(78 \%$; 39) common finding followed by retraction $(50 \% ; 25)$ and air bubbles $(10 \% ; 5)$ (Table 3).

Table-3: Otoscopic findings of the tympanic membrane of the study participants.

\begin{tabular}{|l|l|l|}
\hline \multicolumn{1}{|c|}{ TM appearance } & Number & Percent \\
\hline Dull, lustreless, amber-colored & 39 & 78 \\
\hline Retraction & 25 & 50 \\
\hline Air bubbles & 5 & 10 \\
\hline
\end{tabular}

Impedance audiometry findings showed that all patients had $B$ type curve in either of the ears and stapedial reflex was absent in all the cases. Ear examination revealed that $14 \%$ (7) were classified as peak and $86 \%$ (43) as no peak category (Table $4)$. In the treatment modality, adenoidectomy alone was conducted in 32 (64\%) cases and Adenoidectomy (Ad) cum tonsillectomy ( $T$ ) in 18 $(36 \%)$ cases.

Table-4: Impedance audiometry findings among the study participants.

\begin{tabular}{|l|l|l|}
\hline \multicolumn{1}{|c|}{ Graph type } & \multicolumn{1}{c|}{ Number } & \multicolumn{1}{c|}{ Percent } \\
\hline Peak & 7 & 14 \\
\hline No peak & 43 & 86 \\
\hline Total & 50 & 100 \\
\hline
\end{tabular}

Hearing improvement during the 1st month was $13 \mathrm{~dB}$, at the $3 \mathrm{rd}$ month was $13.2 \mathrm{~dB}$ and at the 6 th month was $12.7 \mathrm{~dB}$ compared to preoperative findings (Table 5). As the p-value is 0.0001 , that is $<5 \%$, hearing improvement at 1 st, $3 \mathrm{rd}$, and 6 th month was statistically significant (Table 5 ).

Table-5: Hearing improvement in $\mathrm{dB}$ from preoperative findings among the study members.

\begin{tabular}{|l|l|l|}
\hline \multicolumn{1}{|c|}{ Duration in months } & \multicolumn{1}{|c|}{ dB } & \multicolumn{1}{c|}{ p-value } \\
\hline 1 st & 13 & $0.0001,<5 \%$ \\
\hline 3 rd & 13.2 & $0.0001,<5 \%$ \\
\hline 6 th & 12.7 & $0.0001,<5 \%$ \\
\hline
\end{tabular}

\section{Discussion}

The present study included children aged 5-12 years, the majority of study members were between 5 - 7 years age group and the mean age was 7.5 years. Brooks et al [7] in their study showed $50 \%$ of the patients were in the age group of $5-7$ years. 
Similar results were mentioned in the Reddy et al study [8]. In the present study, there was a male preponderance. Tos and Stangerup showed that male children had more incidence of SOM than female due to male preponderance of childhood infection [9]. However, Paradise et al. reported that no gender-based difference in the incidence of SOM [10].

In this study, $36 \%$ of children presented with features of associated tonsillitis and $18 \%$ had associated sinusitis. Koko reported that $20.5 \%$ of cases with SOM had features of sinusitis and $5.8 \%$ had tonsillitis [11]. The higher incidence of tonsillitis in the present study can be attributed to poor hygienic living conditions as most of the children belonged to low socioeconomic status. All patients had nasal obstruction/snoring due to adenoid hypertrophy. Hard of hearing was the common symptom related to the ear, followed by fullness. Hard of hearing was also the major complaint in the study conducted by Reddy et al [8].

On otoscopy, dull lustreless amber-colored TM was the common finding seen in $76 \%$ of cases. Retraction of TM with the shortened handle of malleus was seen in $50 \%$. Air bubbles were seen only in $10 \%$ of cases which is seen in the serous type of OM. Most of the children in the present study had very mild hearing loss according to Clark's classification and the average hearing loss was $24.95 \mathrm{~dB}$. In a study conducted by Fiellau Nikolajsen et al [12], the mean hearing loss was 23 $\mathrm{dB}$. Whereas Fria $\mathrm{TJ}$ et al. reported the average hearing loss was $24.5 \mathrm{~dB}$ which correlates with the present study [13]. A study by Schilder, Zielhais, and Venden Brook et al. showed the mean hearing loss was $20 \mathrm{~dB}$ [14] and it was mentioned $26 \mathrm{~dB}$ hearing loss by Dempster and Mackenzie et al [15].

Impedance audiometry was widely used in screening for SOM. As suggested by FiellauNickolajsens classification in 1983. A middle ear pressure of $<100 \mathrm{~mm} \mathrm{H} 2 \mathrm{O}$ was considered abnormal in this study. According to Renvall et al stapedial reflex is considered too sensitive to be used as a screening test in the diagnosis of SOM [16]. In the present study, most children had type $B$ curves and stapedial reflex was negative in all patients. Resolution of SOM was assessed by no peak /peak conversion. Fria et al. reported that $84 \%$ of diagnostic predictability can be attained by using this no-peak/peak criteria [17].
Maw et al. observed that adenoidectomy alone produced no peak/peak conversion in $29.8 \%$ of children [18]. In the present study, also $33 \%$ of children showed no peak/peak conversion at 6 months. However, in the rest of the patients, an improvement in middle ear pressure to varying degrees was observed. Bluestone in 1976 observed that Eustachian tube function improved after adenoidectomy [19]. Maw in 1983 reported that adenoidectomy had a significant therapeutic effect in resolving the effusion in $36-46 \%$ of cases of resistant SOM [20]. The benefit of adenoidectomy could be due to reduction of the bacterial reservoir of the nasopharynx and it also relieves obstruction of the nasopharyngeal end of the eustachian tube leading to better ventilation of the middle ear. The beneficial effect of tonsillectomy could be due to the reduction of ascending infection. Coyle et al also concluded that adenoidectomy is a useful procedure for correction of medically resistant chronic SOM and should be considered as the first-line procedure when surgical treatment is chosen [21].

Paradise and others examined the effect of adenoidectomy in two groups of children with $\mathrm{OME}$ recurring after tympanostomy tube placement. In both, the groups, the outcome for the adenoidectomies children were statistically better than for the control children for both follow-up years, with greater differences in the first than the second year [22].

Maw randomly assigned 103 children from 2-12 years of age with bilateral OME to one of 3 groups: adenotonsillectomy $(n=34)$, adenoidectomy $(n=36)$, or neither $(n=33)$. At surgery, one ear was randomly assigned to receive a tympanostomy tube. At 3, 6, 9, and 12 months, the clearance of effusion in the unoperated ear was recorded. The difference between the two surgical groups and control groups was significant, but the difference between the adenotonsillectomy and adenoidectomy group was not [23].

Myringotomy with ventilation tube insertion for SOM is the commonest procedure in children. The ventilation tube has its complications. Complication includes infection, tympanosclerosis, persistent perforation, and medial displacement of a ventilation tube in the middle ear. Talman et al. reported otorrhea in $6.6 \%$ [24] while Hern et al. reported in $18 \%$ cases [25]. Riley et al. noted tympanosclerosis in $40 \%$ and perforation in $4.3 \%$ of the ears [26]. 
A single shepherd tube alone gives a short-lived effect of 10 months whereas adenoidectomy produces a significantly longer-lasting effect for several years [27]. Myringotomy and aspiration of fluid in some studies showed a dry tap rate up to $34 \%$ [28]. Relationships between nasopharyngeal dimensions and the presence of OM with effusion have been shown [29].

Based on these observations, in the current study adenoidectomy was performed in all patients and tonsillectomy when the indication was present. All patients were regularly followed up postoperatively. During follow up audiometry showed that there was a significant improvement in hearing and a reduction in the $A-B$ gap. The mean $A-B$ gap was $11.95 \mathrm{~dB}, 11.75 \mathrm{~dB}$, and $12.25 \mathrm{~dB}$ at 1 st month, 3rd month, and 6 th month respectively.

By applying a sample t-test the hearing improvement at these consecutive months was found statistically significant compared to preoperative findings. The reduction in A-B gap from 1st month to 3rd month was almost equal, but from $3 r d$ to 6 th month there was an increase in A-B gap which can be attributed to recurrent upper respiratory tract infection which leads to recurrent effusion in few cases at 6months.

\section{Limitations}

Small sample size and short duration of the research are the limitations of this research.

\section{Conclusion}

SOM is one of the common causes of hearing loss in children. The chronicity of SOM may be due to under-treatment or conditions like adenoid hypertrophy, recurrent URTI, sinusitis causing relative dysfunction of ET. In cases where spontaneous resolution does not occur or when medical treatment fails and effusion persists, surgical treatment is usually advocated. Adenoidectomy in children having hypertrophied adenoids with SOM not only relieves ET obstruction but also removes the source of infection. This leads to clearance of middle ear effusion and improvement in hearing postoperatively.

\section{What does the existing study add to the existing knowledge?}

SOM is one of the common clinical findings among children, boys category is slightly more affected.

\section{Authors contribution}

Dr. B Krishna Santosh: Study protocol, design

Dr. K Krishna Sumanth: Benchwork, literature search

Dr. Panda Veeranjaneyulu: Proofreading

Dr. B Deepthi: Article writing, literature search

Dr. K Mamatha: Article writing, literature search

\section{Reference}

01. Teele DW, Klein JO, Rosner B, Bratton L, Fisch GR, Mathieu OR, Porter PJ, Starobin SG, Tarlin LD, Younes RP. Middle ear disease and the practice of pediatrics, Burden during the first five years of life. JAMA. 1983;249(8)1026-1029. doi:10.1001/jama.1983.03330320024025 [Crossref]

02. Derkay CS. Pediatric otolaryngology procedures in the United States- 1977-1987. Int J Pediatr Otorhinolaryngol. 1993;25(1)1-12.

doi: 10.1016/0165-5876(93)90004-m [Crossref]

03. Cristino JM. Correlation between consumption of antimicrobials in humans and development of resistance in bacteria. Int J Antimicrob Agents. 1999;12(3)199-202.

doi: $10.1016 / \mathrm{s} 0924-8579(99) 00052-7 \quad$ [Crossref]

04. Gates GA. Acute otitis media and otitis media with effusion, In- Cummings CW, Flint PW, Haughey BH, Robbins KT, Thomas JR, Harker LA, Richardson MA, Schuller DE editors. Pediatric Otolaryngology- Head and Neck Surgery, 4th ed, USA- Mosby. 2005;4445-4468. [Crossref]

05. Clark JG. Uses and abuses of hearing loss classification. ASHA. 1981;23(7)493-500. [Crossref]

06. George Browning. Otitis media with effusion, Scott-Brown's Otolaryngology. 7th ed, Gleeson M Great Britain, Arnold. 2008;3105-3125. [Crossref]

07. Brooks D. School screening for MEE. Ann Otol Rhinol Laryngol. 1976;85(12)223-229. [Crossref]

08. Reddy VG. Secretory otitis media. Indian J Otol. 1998;4(4)157-60.

[Crossref] 
09. Tos M, Stangerup SE. Secretory otitis and pneumatization of the mastoid process- sexual differences in the size of the mastoid air cell system. Am J Otolaryngol. 1985;6(3)199-205. doi: $10.1016 /$ S0196-0709(85)80085-5 [Crossref]

10. Paradise $\mathrm{JL}$, Rockette $\mathrm{HE}$, Colborn DK, Bernard BS, Smith CG, Kurs-Lasky M, et al. Otitis media in 2253 Pittsburgh-area infants- Prevalence and risk factors during the first 2 years of life. Pediatr. $1997 ; 99 ; 318$.

doi: 10.1542/peds.99.3.318 [Crossref]

11. Kokko E, Palva T. Clinical results and complications of tympanostomy. Ann Otol Rhinol Laryngol. 1979;85(2)222-226.

doi: $10.1177 / 000348947608505252$ [Crossref]

12. Maw AR. Otitis media with effusion, Adams DA, C Innamond MJ, Scott Brown's paediatric Otolaryngology 6th edition, Oxford. Butterworth Heinemann. 1997;6;6/7/1-6/7/17.

[Crossref]

13. Fria TJ, Cantekin EI, Eichler JA. Hearing acuity of children with otitis media with effusion. Arch Otolaryngol. 1985;111(1)10-16.

doi: $\quad$ 10.1001/archotol.1985.00800030044003 [Crossref]

14. Anne GM, Schilder Gerhard A, Zielhuis Paul Van Den Broek. The otological profile of a cohort of Dutch 7,5-8 year olds. Clin Otolaryngol. $1993 ; 18(1) 48-54$.

doi: $10.1111 /$ j.1365-2273.1993.tb00809.x [Crossref]

15. Dempster JH, K Mackenzie. Tympanometry in the detection of hearing impairments associated with otitis media with effusion. Clin Otolaryngol. 1991;16(2)157-159.

doi: 10.1111/j.1365-2273.1991.tb01967.x [Crossref]

16. Renvall $U$, Holmquist J. Tympanometry revealing middle ear pathology. Ann Otol Rhinol Laryngol. $1976 ; 85(2) 209-215$.

doi: $10.1177 / 000348947608505239$ [Crossref]

17. Maw AR. Secretory Otitis Media, In Ludman $H$, Wright $\mathrm{T}$ editors, Diseases of the ear. 6th ed, London- Arnold. 2006;361-373.

[Crossref]
18. Maw AR, Herod F. Otoscopic impedance and audiometric findings in glue ear treated by aden oidectomy and tonsillectomy- A prospective ran domized study. Lancet. 1986;327(8495)1399-

1402. doi: 10.1016/s0140-6736(86)91552-7 [Crossref]

19. Bluestone CD, Beery QC. Concepts on the pathogenesis of MEE. Ann Otol, Rhinol Laryngol. $1976 ; 85(25) 182-186$.

[Crossref]

20. Maw AR. Chronic otitis media with effusion (glue ear) and adenotonsillectomy- a prospective randomized control study. BMJ. $1983 ; 127(6405) 1586-1588$.

doi: $\quad 10.1136 / \mathrm{bmj} .287 .6405 .1586 \quad$ [Crossref]

21. Coyle PC, Croxford R, MC Isaac W, Feldman W, Friedberg J. The role of Adjuvant adenoidectomy $\&$ tonsillectomy in the out of the insertion of tympanostomy tube. $\mathrm{N}$ Engl J Med. 2004;344(16)1188-1195.

doi: $10.1056 /$ NEJM200104193441602 [Crossref]

22. JL Paradise, CD Bluestone, KD Rogers, FH Taylor, DK Colborn, RZ Bachman, BS Bernard, $\mathrm{RH}$ Schwarzbach. Efficacy of adenoidectomy for recurrent otitis media in children previously treated with tympanostomy-tube placementResults of parallel randomized and nonrandomized trials. J Am Med Assoc. 1990;263(15)2066-2073.

[Crossref]

23. Kilic R, Safac MA, Ozedek A, Gocmen H, Kilic D, Samim E. Effect of 23 valent pneumococcal polysaccharide and haemophilus influenza conjugated vaccines on the clinical course of otitis media with effusion. Laryngoscope. 2002;112(11)2042-2045.

doi: $10.1097 / 00005537-200211000-00024$ [Crossref]

24. Talmon $Y$, Gadman $H$, Samet A, Gilbey $P$, Letichevsky $V$. Ventilation with selfmanufactured polyethylene $T$ tubes for the treatment of children with middle ear effusion. J Laryngol Otol. 2001;115(9)699-703.

doi: $10.1258 / 0022215011908937$ [Crossref]

25. Hern JD, Hasnie A, Shah NS. A long-term review of the shah pavement tube. J Laryngol Otol. $1995 ; 109(4) 277-280$.

doi: $\quad 10.1017 / \mathrm{s} 0022215100129925$

[Crossref] 
26. Riley DN, Herberger S, Mc Bride G, Law K. Myringotomy and ventilation tube Insertion- $a$ ten-year follow-up. J Laryngol Otol. $1997 ; 111(3) 257-261$.

doi: $\quad 10.1017 / \mathrm{s} 0022215100137016 \quad$ [Crossref]

27. Maw R, Bawden R. Spontaneous resolution of severe chronic glue ear in children and the effect of adenoidectomy, tonsillectomy, and insertion of ventilation tubes (grommets). BMJ. $1993 ; 306(6880) 756-760$.

doi: $10.1136 / \mathrm{bmj} .306 .6880 .756$ [Crossref]
28. Black NA, Sanderson CFB, Freeland AB, Vessey MP. A randomized controlled trial of surgery for glue ear. BMJ. 1990;300(6739)1551-1556.

doi: $\quad 10.1136 / \mathrm{bmj} .300 .6739 .1551 \quad$ [Crossref]

29. Maw AR, Smith IM, Lance GN. Lateral cephalometric analysis of children with OME- A comparison with age and sex matched controls. J Laryngol Otol. 1991;105(2)71-77.

doi: $\quad 10.1017 /$ S0022215100114999 [Crossref] 